\title{
Oral Powder Dosage Form
}

National Cancer Institute

\section{Source}

National Cancer Institute. Oral Powder Dosage Form. NCI Thesaurus. Code C91171.

A powder intended for administration through the mouth. 